\section{Bone loss in inflammatory Bowel disease: our multicentric study}

\author{
Alessandro Geraci,1 Giovanni Tomasello,2 \\ Provvidenza Damiani, 3 \\ Guido Mazzoccato, 1 Luca Marinato, 4 \\ Salvatore Benigno, 5 Andrea Nastasi, 1 \\ Mauro Gasparo 1 \\ 1Orthopaedic and Traumatology \\ Department, Santa Maria del Prato \\ Hospital, Feltre; \\ 2Department of Surgery, GEN.UR.TO, \\ University of Palermo, Palermo; \\ 3Emergency Medicine and fisrt aid \\ operating unit, Emergency department, \\ University of Palermo; \\ ${ }^{4}$ Orthopaedic and Traumatology \\ Department, Santa Maria degli Angeli \\ Hospital, Pordenone; \\ ${ }^{5}$ Radiological institute, University \\ of Palermo, Italy
}

\section{Abstract}

Patients with inflammatory bowel disease are at increased risk of developing disorder in bone and mineral metabolism The study was aimed to determine if inflammatory bowel disease (IBD) is a risk factor for osteoporosis in 103 adult patients. We included 103 IBD patients, 67 patients with Crohn's disease (CD) and 36 with ulcerative colitis (UC). Bone mineral density was measured by dual-energy X-ray absorptiometry. We used $\mathrm{T}$ score to express bone loss (osteopenia: $-2.5 \mathrm{SD}<\mathrm{T}<-1$ SD, osteoporosis: $\mathrm{T}<-2.5 \mathrm{SD}$ ). Plain $\mathrm{x}$-rays were examined to search for vertebral compression or spontaneous fractures before DEXA. Among the 103 patients, $47.7 \%$ exhibited osteopenia of the femoral neck and $62.3 \%$ of the lumbar spine, with no significant difference between $\mathrm{CD}$ and UC. The prevalence of osteoporosis of the lumbar spine was significantly higher in CD patients $(41.2 \%$ versus $8.7 \%$ ). Osteoporosis is frequent in IBD patients, especially in CD patients. Female gender, malnutrition (body mass index $<20$ $\mathrm{kg} / \mathrm{m}^{2}$ ), disease course ( $>2$ years) and active disease would be risk factors of bone mineral loss in IBD.

\section{Introduction}

Patients with inflammatory bowel disease (IBD) are at increased risk of developing disorder in bone and mineral metabolism.
Osteopenia and osteoporosis are frequently seen in Crohn's disease (CD) and ulcerative colitis. ${ }^{1,2}$ The prevalence of osteoporotic fractures is strikingly high, both in females and males; depending on the population studied the prevalence of osteoporosis has been reported to range from $12-42 \%$ in patients with IBD. ${ }^{3}$ It has been suggested that the pathogenesis of osteoporosis in patients with IBD is multifactorial (Table 1). ${ }^{4}$ Disease activity and duration, low body weight or body mass index (BMI), calcium and vitamin D deficiency, small bowel involvement or resection, gender, the use of glucocorticoids to control disease activity, increasing age immobilization and life style risk factors (e.g. smoking, excessive alcohol intake, physical inactivity) as well as genetic factors have been implicated. ${ }^{5-7}$ Not all studies have demonstrated a relationship between corticosteroid use and low BMD in IBD patients. In one BMD study performed on CD patients; it was shown that both groups who had a low life-time corticosteroid dose therapy with or without dietary manipulation, had a similar BMD to that of agematched normal controls. Whereas, BMD was significantly reduced in those treated predominately by corticosteroids. ${ }^{8}$ However, it is difficult to separate the effects of corticosteroids from those of disease activity. ${ }^{9}$ Although corticosteroids may be mechanistically responsible for bone loss, their use may also serve as a marker for more severe disease activity that is responsible for bone loss. Bone density and growth are determined by the combination of anabolic osteoblast activity (bone formation) and catabolic osteoclast activity (bone resorp-
Correspondence: Alessandro Geraci, Alessandro Geraci, Hospital Santa Maria del Prato, via Bagnolis sur Ceze 3, Feltre, Italy.

Tel. +39.0439 .883520 - Fax: +39.0439 .883538 .

E-mail: geracialessandro@libero.it

Key words: osteoporosis, Crohn's disease, dexa, inflammatory bowel disease, osteoporosis, ulcerative colitis.

Contributions: all the authors contributed equally to the present work.

Conflict of interest: the authors report no conflicts of interest.

Received for publication: 14 0ctober 2010.

Accepted for publication: 7 March 2011.

This work is licensed under a Creative Commons Attribution 3.0 License (by-nc 3.0).

(C)Copyright A. Geraci et al., 2011

Licensee PAGEPress, Italy

Endocrinology Studies 2011; 1:e3

doi:10.4081/es.2011.e3

Table 1. Risk factor osteoporosis in inflammatory Bowel disease.

Increasing age

Malnutrition

Low Body mass index

Use of corticosteroids

Immobilization

Malabsorption of vitamin $\mathrm{D}$, calcium and vitamin $\mathrm{K}$ Hypogonadism

Smoking

Chronic inflammatory state

Table 2. Differential diagnosis between Crohn's disease and ulcerative colitis according to endoscopic findings.

\begin{tabular}{lcc} 
& Crohn's disease & Ulcerative colitis \\
Involvement & Discontinous & Continous \\
Rectal involvement & $20 \%$ & Always \\
\hline Vessels & Often normal & Abnormal/ \\
Eryhthema/edema & ++ & lacking \\
\hline Vulnerability & $(+)$ & +++ \\
Bleeding & $(+)$ & +++ \\
\hline Pus/mucus & + & +++ \\
Local ulcers & +++ & +++ \\
\hline Fissural ulcers & +++ & $(+)$ \\
Granularity & $(+)$ & $(+)$ \\
\hline Clobbestone pattern & +++ & +++ \\
Pseudopolyps & ++ & --- \\
\hline Strictures & ++ & +++
\end{tabular}

Table 3. Truelove and Witts' classification of severity of ulcerative colitis.

\begin{tabular}{lccc} 
Activity & Mild & Moderate & Severe \\
Number of bloody stools per day $(\mathrm{n})$ & $<4$ & $4-6$ & $>6$ \\
Temperature $\left({ }^{\circ} \mathrm{C}\right)$ & Afebrile & Intermediate & $>37.8$ \\
\hline Heart rate $($ beats per minute) & Normal & Intermediate & $>90$ \\
Haemoglobin $(\mathrm{g} / \mathrm{dL})$ & $>11$ & $10.5-11$ & $<10.5$ \\
\hline Erythrocyte sedimentation rate $(\mathrm{mm} / \mathrm{h})$ & $<20$ & $20-30$ & $>30$
\end{tabular}


tion), as well as the activity of chondrocytes (cartilage formation needed to extend bone length). During normal bone growth, chondrocytes continually mature and produce cartilage at the growth plate to allow bones to lengthen (endochondral bone formation). Osteoclasts resorb the cartilage and areas of existing bone and osteoblasts form. The regulation of bone metabolism involves a complex interplay between different factors, including sex steroids. ${ }^{10}$ As of today, little is known about the prevalence of sex steroid deficiency in male CD patients and its contribution to bone loss and osteoporosis. In postmenopausal osteoporosis, the importance of sex steroid deficiency, especially estradiol $\left(\mathrm{E}_{2}\right)$ deficiency, is well established.11 Women with CD ed UC are at an increased risk of amenorrhoea and premature menopause. Osteoporosis is often considered to be a disease of women, men lose half as much bone with aging and have one third as many fragility fractures as do women. Previous studies investigating testosterone (T) and the gonadotropins follicle stimulating hormone (FSH) and luteinizing hormone (LH), reported lower than normal T levels in 4/48 (8\%) male $\mathrm{CD}$ patients with the free androgen index (FAI) low in three patients and normal gonadotropins. ${ }^{12} \mathrm{~T}$ was positively associated with osteocalcin. Others report T deficiency in 20/45 (44.4\%) male IBD patients but no effect on bone density and metabolism was detected.13 Lower than normal dehydroepiandrosterone sulfate (DHEAS) levels have been found in IBD patients, in part dependent on previous glucocorticoid treatment. High cortisol and low DHEAS levels were associated with higher humoral inflammatory activity, and vice versa. ${ }^{14}$ Lower levels of DHEAS plasma levels in male IBD patients were associated with lower BMD and with higher deoxypyridinoline excretion. DHEAS correlated with BMD at the lumbar spine and femoral neck. In the literature, the reported prevalence of osteoporosis/ osteopenia in IBD varies from 7-56\%.15 A retrospective study of a Caucasian population showed a $40 \%$ increase in the risk of fracture compared to healthy controls. ${ }^{16} \mathrm{CD}$ seems to be associated with a slightly higher risk than UC does for osteoporosis and subsequent fractures, although this has been disputed in some studies. ${ }^{17}$ With the advent of dual-energy X-ray absorptiometry (DXA), it is easy to measure bone mineral density (BMD) non-invasively. BMD results are typically expressed as the number of standard deviations (SD) above or below the mean for a young adult population (T-score) or an agematched population (Zscore). In most studies, either T- or Z scores have been used in evaluating predictive factors of low bone density in IBD, making comparison of results difficult. World Health Organisation ${ }^{18}$ diagnostic criteria (a bone density 2.5 or more standard deviation units below the mean value for young adults) report rates of $13-42 \% 19,20$ The aim of this cross sectional study was to determine the prevalence of osteoporosis in an unselected group of patients with CD e UC and to identify the relative importance of possible risk factors and the mechanism of bone loss.

\section{Materials and Methods}

From November 2007 to March 2010, we enrolled all consecutive IBD patients aged 20-80 years who attended our department. The study was performed according to the Helsinki declaration. All patients were informed about the nature of the study and gave their consent to participate. The diagnosis of Crohn's disease (CD) or ulcerative colitis (UC) had been established on the basis of classical clinical, endoscopic, histological, and radiographic criteria (Table 2). Disease activity was determined with the Truelove and Wittes criteria for UC ${ }^{21}$ (Table 3 ) and the activity index for CD (Table 4).22 Exclusion criteria were pregnancy; uncontrolled diabetes; renal, hepatic, cardiovascular or psychiatric disease; rheumatoid arthritis; ankylosing spondylitis; untreated thyroid disease; primary sclerosing cholangitis; or treatment with teriparatide, calcitonin, bisphosphonates, fluoride, androgens, active metabolites of vitamin D within the past 6 mo. Weight and height were measured without shoes and with light indoor clothing. The BMI was calculated as weight/height ${ }^{2}\left(\mathrm{~kg} / \mathrm{m}^{2}\right)$. BMD was measured with diphotonic x-ray absorptiometry (DEXA) of the lumbar spine and the neck of the left femur. Results were expressed as T score (osteopenia: -2.5 standard deviation (SD) $<\mathrm{T}<-1$ SD, osteoporosis: T<-2.5 SD) (Figure 1). ${ }^{23}$ Plain $\mathrm{x}$-rays of the pelvis and lumbar spine (anteroposterior and lateral view) were examined to search for vertebral compression (Figure 2) or spontaneous fractures before DEXA. Cumulative dose of corticosteroids was obtained by multiplying all doses of corticosteroids prescribed either orally or parenterally by the total duration of disease and relative potency to hydrocortisone (CCD=Potency* Dose*Duration). ${ }^{24}$

Table 1. Activity index for Chron's disease.

\begin{tabular}{|c|c|c|}
\hline Disease activity index & X Factor & Subto \\
\hline $\begin{array}{l}\text { Total number of liquid or very soft s } \\
\text { tools in the previous } 7 \text { days or, } \\
\text { for stoma patients, total number } \\
\text { of bags emptied. }\end{array}$ & $\mathrm{X} 2$ & $=$ \\
\hline $\begin{array}{l}\text { Sum abdominal pain/cramps ratings } \\
\text { (total for previous } 7 \text { days): } \\
0=\text { none, } 1=\text { mild, } 2=\text { moderate, } 3=\text { severe }\end{array}$ & $\mathrm{X} 5$ & $=$ \\
\hline $\begin{array}{l}\text { General well being (total for previous } 7 \text { days): } \\
0=\text { generally well, } 1=\text { slightly under par, } 2=\text { poor, } \\
3=\text { very poor, } 4=\text { terrible }\end{array}$ & $\mathrm{X} 7$ & $=$ \\
\hline \multicolumn{3}{|c|}{ Categories currently present and presumed to be related to Crohn's disease: $0=$ none; $1=$ yes } \\
\hline $0=$ arthritis/arthralgia & $\mathrm{X} 20$ & $=$ \\
\hline $\begin{array}{l}0=\text { iritis/uveitis } \\
0=\text { erythema nodosum/pyoderma gangrenosum/aphithous stomatis }\end{array}$ & $\begin{array}{l}X 20 \\
X 20\end{array}$ & $\begin{array}{l}= \\
=\end{array}$ \\
\hline $\begin{array}{l}0=\text { anal fissure, fistula, other abcess } \\
0=\text { other fistula }\end{array}$ & $\begin{array}{l}X 20 \\
X 20\end{array}$ & $\begin{array}{l}= \\
=\end{array}$ \\
\hline ( $=$ fever over $37,8^{\circ} \mathrm{C}$ during the previous 7 days & $\mathrm{X} 20$ & $=$ \\
\hline $\begin{array}{l}\text { During the previous } 7 \text { days has patient received } \\
\text { antidiarrheal therapy at least once: OR } \\
\text { During the previous } 7 \text { days has patient received opiate } \\
\text { therapy on each of the } 7 \text { days: } \\
\begin{array}{l}0=\text { no } \\
1=\text { yes }\end{array}\end{array}$ & $\mathrm{X} 30$ & $=$ \\
\hline
\end{tabular}

Abdominal mass:

$0=$ none $; 2$ = questionable $; 5$ = difinite

Hematocrit:

$\mathrm{X} 10=$

Males: $(47-\mathrm{Hct})=\mathrm{SUM}$

Females: $(42-\mathrm{Hct})=$ SUM

(Standard weight- actual body weight)

Standard weight

$\mathrm{X} 100$ (if this value is $=$
less than -10 then
enter -10 )

$\mathrm{X} 1$

TOTAL=

X6 =
$=$

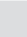

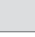




\section{Results}

The study population included 103 patients (61 women and 42 men). Mean age was $49 \pm 15$ years (range 20-80). Sixty-seven patients had $\mathrm{CD}$ and 36 UC. Mean disease duration was $78.5 \pm 65.6$ months for $\mathrm{CD}$ and $60.3 \pm 45.1$ for UC. CD was ileal in $19.7 \%$ of patients, ileocolonic in $50.7 \%$ and colonic in $29.6 \%$. For UC, the descending colon was involved in $78.3 \%$ of patients and $21.7 \%$ had pancolonic disease. The disease was active in $39.3 \%$ of patients with CD and $52.5 \%$ of those with UC. Intestinal resection had been performed in $21.7 \%$ of patients with CD and $4.7 \%$ of patients with UC had undergone coloproctectomy with ileoanal anastomosis. 47 patients (31 CD and $16 \mathrm{UC}$ ) had received corticosteroid treatments. The cumulative dose was significantly higher in $\mathrm{CD}$ patients $(5.4 \geq 6.4$ vs $2.5 \geq 5.8 \mathrm{mg}$ prednisone equivalent, $\mathrm{P}<0.05)$. There was no history of corticosteroid treatment in 27 patients (36.9\%). BMI was significantly lower in patients with CD $\left(18.3 \pm 5.7\right.$ vs $\left.22.7 \pm 5.3 \mathrm{~kg} / \mathrm{m}^{2}, \mathrm{P}<0.01\right)$. Nineteen women were menopaused (8 CD, $11 \mathrm{UC}$ ). Vertebral compression was observed on the $\mathrm{x}$ rays of eleven patients (all female). Six patients reported traumatic fracture of the wrist, two patients vertebral fractures. Among the 103 patients, $47.7 \%$ exhibited osteopenia of the femoral neck and $62.3 \%$ of the lumbar spine, with no significant difference between $\mathrm{CD}$ and UC. The prevalence of osteoporosis of the lumbar spine was significantly higher in CD patients $(41.2 \%$ vs $8.7 \%, \mathrm{P}<0.01)$. There was a similar trend for the femoral neck $(32.1 \%$ vs $13.1 \%, \mathrm{P}<0.09$ ) (Table 5).

\section{Discussion}

Patients with IBD have an increased risk of developing osteoporosis, associated with fragility fractures and morbidity. The overall prevalence of osteoporosis in IBD is approximately $15 \%$ but is more prevalent with older age; the overall relative risk of fractures is $40 \%$ greater when compared to the general population. ${ }^{25}$ Vertebral fractures often occur spontaneously or after minimal trauma and it is estimated that only one-third of vertebral fractures come to clinical attention. ${ }^{26} \mathrm{X}$-ray images of the spine most commonly show wedge or compression deformities. A variety of studies have demonstrated both decreased bone mineral density (BMD) in patients with IBD, and increased rates of bone loss when followed longitudinally27,28 in comparison to healthy controls. The current Gold standard for measuring bone mass is dual-energy $\mathrm{X}$-ray absorptiometry (DEXA). The prevalence of osteoporosis in IBD is very variable. This variation is related to dif-
Table 5. Results of our study.

\begin{tabular}{lcc} 
& Crohn's disease & Ulcerative colitis \\
Number of patients & 67 & 36 \\
Mean disease duration & $78.5 \pm 65.6 \mathrm{months}$ & $60.3 \pm 43.61$ months \\
\hline Activity of disease & $39.3 \%$ & $52.5 \%$ \\
Corticosteroid treatment & 31 patients & 16 patients \\
\hline Body mass index & $18.3 \pm 5.7 \mathrm{Kg} / \mathrm{m}^{2}$ & $22.7 \pm 51.3 \mathrm{Kg} / \mathrm{m}^{2}$ \\
Women menopaused & 8 patients & 1 patient \\
\hline Osteoporosis of lumbar spine & $41.2 \%$ & $8.7 \%$ \\
Osteoporosis of femoral neck & $32.1 \%$ & $13.1 \%$ \\
\hline
\end{tabular}

\begin{tabular}{|c|c|c|c|c|c|}
\hline \begin{tabular}{|l} 
Paziente: \\
Data di nascita:
\end{tabular} & C $\quad, \quad M \quad$ M & ID paziente: & 4432 & & \\
\hline Altezza / Peso: & $158,0 \mathrm{~cm} \quad 68,0 \mathrm{~kg}$ & Misurato: & $19 / 08 / 08$ & 11.40 .57 & $(10,50)$ \\
\hline Sesso / Etnia: & Donna Bianco & Analizzato: & $19 / 08 / 08$ & 11.44 .57 & $(10,50)$ \\
\hline
\end{tabular}
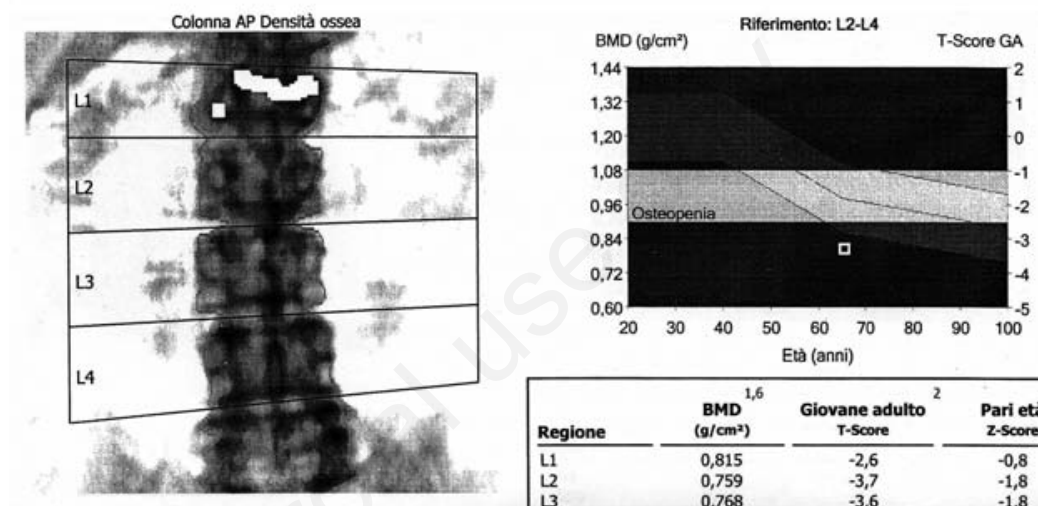

\begin{tabular}{|c|c|c|c|}
\hline Regione & $\begin{array}{c}\mathrm{BMD}^{1,6} \\
\left(\mathrm{~g} / \mathrm{cm}^{2}\right)\end{array}$ & $\begin{array}{c}\text { Giovane adulto }^{2} \\
\text { T-Score }\end{array}$ & $\begin{array}{c}\text { Pari età } \\
\text { z-score }\end{array}$ \\
\hline L1 & 0,815 & $-2,6$ & $-0,8$ \\
\hline 12 & 0,759 & $-3,7$ & $-1,8$ \\
\hline 13 & 0,768 & $-3,6$ & $-1,8$ \\
\hline 14 & 0,881 & $-2,7$ & $-0,8$ \\
\hline L1-13 & 0,777 & $-3,3$ & $-1,4$ \\
\hline L1-L4 & 0,806 & $-3,1$ & $-1,3$ \\
\hline $12-14$ & 0,804 & $-3,3$ & $-1,5$ \\
\hline
\end{tabular}

COMMENT:

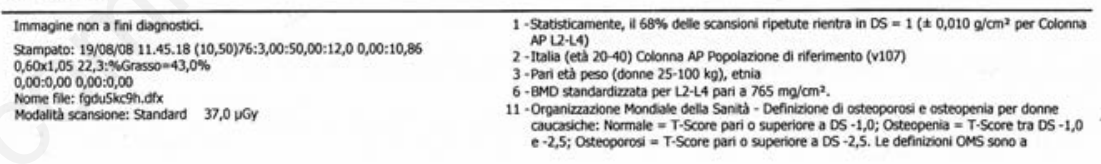

Figure 1. Example of vertebral diphotonic x-ray absorptiometry.

ferences in study populations and methodologies used to measure BMD and to select explored sites. The prevalence of bone loss in our patients is in agreement with other studies using DEXA at the same bone sites . Some studies have reported lower BMD in CD compared with UC. ${ }^{29,30}$ Dresner Polack et al. ${ }^{31}$ noted a trend towards lower BMD in CD, in agreement with our findings where there was a trend towards lower BMD in the femoral neck in CD compared with UC. This bone loss was significantly in the lumbar spine. We also demonstrated a trend towards an association between disease activity and osteoporosis of the femoral neck and the spine, between gender and osteoporosis of the femoral neck (women were more osteoporotic), and between BMI and disease duration with spinal osteoporosis. This associ-

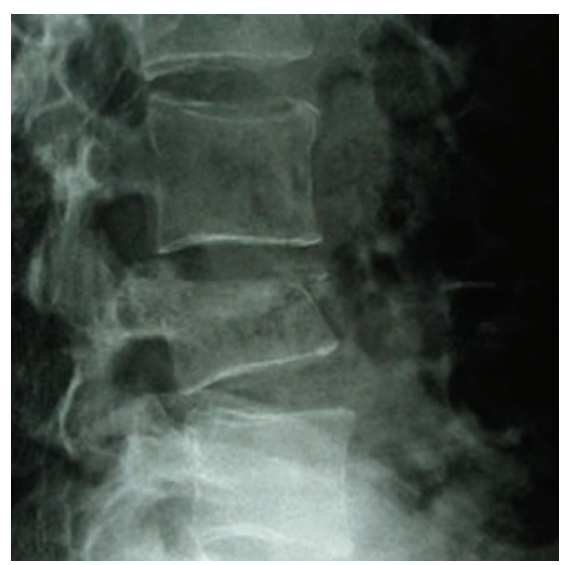

Figure 2. Radiographic exam of a vertebral compression. 
ation was not observed with cumulative steroid dose. Ardizzone et al. ${ }^{32}$ demonstrated that disease duration affects bone loss in the femoral neck in patients with CD. Our study failed to demonstrate the role of corticosteroid therapy in bone loss, probably due to insufficient statistical power. In our study, 56 patients had never received steroids. Fifteen of them (25.9\%) presented osteoporosis of the femoral neck and eight osteoporosis of the lumbar spine. Roux $e t$ $a l .{ }^{33}$ presented a longitudinal study where $34 \%$ of patients with significant bone loss had not received steroids during the study period. Ghosh et al. ${ }^{34}$ reported a significant fall in BMD in $\mathrm{CD}$ patients before corticosteroid treatment.

\section{Conclusions}

Patients with IBD are at risk for reduced BMD and the development of osteoporosis. A screening DXA to assess BMD is warranted for patients with $\mathrm{CD}$ and ulcerative colitis who are postmenopausal, have had vertebral fractures, or have been on prolonged corticosteroids. In conclusion, our study demonstrated that IBD patients, and particularly CD patients, have a high risk of osteoporosis. This complication appears to be related to nutritional status, disease duration, and disease activity. These results suggest patients with IBD should be monitored and treated early for bone loss in order to reduce the risk of osteoporotic fractures.

\section{References}

1. Bartram SA, Peaston RT, Rawlings DJ, et al. Multifactorial analysis of risk factors for reduced bone mineral density in patients with Crohn's disease. World J Gastroenterol 2006;12:5680-6.

2. Bjarnason I, Macpherson A, Mackintosh C, et al. Reduced bone density in patients with inflammatory bowel disease. Gut 1997;40: 228-33.

3. Van Hogzand RA, Hamdy NA. Skeletal morbidity in inflammatory bowel disease. Scand J Gastroenterol Suppl 2006;243:5964.

4. Bernstein CN, Leslie WD, Leboff MS. AGA technical review on osteoporosis in gastrointestinal diseases. Gastroenterology 2003;124:795-841.

5. Schulte C, Dignass AU, Mann K, Goebell H. Reduced bone mineral density and unbalanced bone metabolism in patients with inflammatory bowel disease. Inflamm Bowel Dis 1998;4:268-75.

6. Andreassen H, Hylander E, Rix M. Gender, age, and body weight are the major predictive factors for bone mineral density in
Crohn's disease: a case-control crosssectional study of 113 patients. AM J Gastroenterol 1999;94: 824-828.

7. Bernstein CN. Osteoporosis and other complications of inflammatory bowel disease. Curr Opin Gastroenterol 2002;18: 428-34.

8. Dear KL, Compston JE, Hunter J0. Treatments for Crohn's disease that minimise steroid doses are associated with a reduced risk of osteoporosis. Clin Nutr 2001;20:541-6.

9. Lora FL, Amarante HM, Pisani JC, et al. Bone mineral density evaluation in inflammatory bowel disease patients. Arg Gastroenterol 2005;42:201-5.

10. Riggs BL, Khosla S, Melton LJ III. A unitary model for involutional osteoprosis: estrogen deficiency causes both type I and type II osteoporosis in postmenopausal women and contributes to bone loss in ageing men. J Bone Miner Res 1998;13:763-73.

11. Khosla S, Melton LJ 3rd, Atkinson EJ, et al. Relationship of sex steroid levels and bone turnover markers with bone mineral density in men and women: a key role for bioavailable estrogen. J Clin Endocrinol Metab 1998;83:2266-74.

12. Robinson RJ, Iqbal SJ, Al-Azzawi F, et al. Sex hormone status and bone metabolism in men with Crohn's disease. Aliment Pharmacol Ther 1998;12:21-5.

13. Szathmári M, Vásárhelyi B, Treszl A, et al. Association of dehydroepiandrosterone sulfate and testosterone deficiency with bone turnover in men with inflammatory bowel disease. Int J Colorectal Dis 2002; 17:63-6.

14. Straub RH, Vogl D, Gross V, et al. Association of humoral markers of inflammation and dehydroepiandrosterone sulfate or cortisol serum levels in patients with chronic inflammatory bowel disease. Am J Gastroenterol 1998;93:2197-202.

15. Card T, West J, Hubbard R, Logan RF. Hip fractures in patients with inflammatory bowel disease and their relationship to corticosteroid use: a population based cohort study. Gut 2004;53:251-5.

16. Stockbrügger RW, Schoon EJ, Bollani S, et al. Discordance between the degree of osteopenia and the prevalence of spontaneous vertebral fractures in Crohn's disease. Aliment Pharmacol Ther 2002;16: 1519-27.

17. Loftus EV Jr, Achenbach SJ, Sandborn WJ, et al. Risk of fracture in ulcerative colitis: a population-based study from Olmsted County, Minnesota. Clin Gastroenterol Hepatol 2003;1:465-73.

18. Pollak RD, Karmeli F, Eliakim R, et al. Femoral neck osteopenia in patients with inflammatory bowel disease. Am J Gastro enterol 1998;93:1483-90.

19. Bjarnason I, Macpherson A, Mackintosh C, et al. Reduced bone density in patients with inflammatory bowel disease. Gut 1997;40: 228-33.

20. Compston JE, Judd D, Crawley EO, et al. Osteoporosis in patients with inflammatory bowel disease. Gut 1987;28:410-5.

21. Truelove SC, Witts LJ. Cortisone in ulcerative colitis. Br Med J 1955;2:1041-6.

22. Best WR, Becktel JM, Singleton JW, Kern F Jr. Development of a Crohn's disease activity index. National Cooperative Crohn's Disease Study. Gastroenterology 1976; 70:439-44.

23. Kanis JA, Melton LJ III, Christiansen C, et al. The diagnosis of osteoporosis. J Bone Miner Res 1994;9:1137-41.

24. De Jong DJ, Corstens FH, Mannaerts L, et al. Corticosteroid-induced osteoporosis: does it occur in patients with Crohn's disease? Am J Gastroenterol 2002;97:2011-5.

25. American Gastroenterological Association medical position statement: guidelines on osteoporosis in gastrointestinal diseases. Gastroenterology 2003;124:791-4.

26. Satsangi J. Compston, Osteoporosis associated with inflammatory bowel disease, in Inflammatory bowel disease. Churchill Livingstone 2003;637-48.

27. Staun M, Tjellesen L, Thale M, et al. Bone mineral content in patients with Crohn's disease. A longitudinal study in patients with bowel resections. Scand J Gastroenterol 1997;32:226-32.

28. Motley RJ, Clements D, Evans WD, et al. A four-year longitudinal study of bone loss in patients with inflammatory bowel disease. Bone Miner 1993;23:95-104.

29. Ghosh S, Cowen S, Hannan WJ, Ferguson A. Low bone mineral density in Crohn's disease, but not in ulcerative colitis, at diagnosis. Gastroenterology 1994;107: 1031-9.

30. Jahnsen J, Falch JA, Aadland E, Mowinckel $\mathrm{P}$. Bone mineral density is reduced in patients with Crohn's disease but not in patients with ulcerative colitis: a population based study. Gut 1997;40:313-9.

31. Dresner Pollak RD, Karmeli F, et al. Femoral neck osteopenia in patients with inflammatory bowel disease. Am J Gastroenterol 1998;93:1483-90.

32. Ardizzone S, Bollani S, Bettica P, et al. Altered bone metabolism in inflammatory bowel disease: there is a difference between Crohn's disease and ulcerative colitis. J Intern Med 2000;247:63-70.

33. Roux C, Abitbol V, Chaussade S, et al. Bone loss in patients with inflammatory bowel disease: prospective study. Osteoporos Int 1995;5:156-60.

34. Ghosh S, Cowen S, Hannan WJ, Ferguson A. Low bone mineral density in Crohn's disease, but not in ulcerative colitis, at diagnosis. Gastroenterology 1994;107: 1031-9. 